\title{
Contemporary Status of Research in Material Science for Designing the Advanced Smart Medical Compression Stockings
}

\author{
Harishkumar Narayana and Jinlian Hu* \\ Institute of Textiles and Clothing, The Hong Kong Polytechnic University, Hong Kong
}

Submission: September 28, 2017; Published: November 15, 2017

*Corresponding author: Jinlian Hu, Institute of Textiles and Clothing, The Hong Kong Polytechnic University, Hung Hom, Kowloon, QT 807, Hong Kong, Tel: +852 2766 6437; Fax: +852 -2773 1432; Email: tchujl@polyu,edu.hk

\begin{abstract}
Compression stockings are considered as a gold standard for the treatment of phlebological and lymphatic diseases with an aid of compression therapy. It has been a great challenge for health practitioners and technocrats involved in designing the stockings to maintain the constant pressure for long time. Currently, there are several shortcomings of the stockings with lack of innovation in material research. At present, compression stockings are made of continuous strand of textile fibers including Nylon and Lycra or spandex. There is a need of scientific approach to incorporate any alternative smart material, which could allow to have the external pressure control. The major problems, challenges involved, and our research approach to solve the present shortcomings are highlighted. The present status of the material research towards designing the smart medical compression stockings and our significant pioneer contributions are also well discussed here.
\end{abstract}

Keywords: Compression stockings; stress-memory; Medical textiles; Memory fibers; Compression therapy; Memory polymer

\section{Introduction}

Researchers have been continuously working in the field of materials science to develop novel materials related to healthcare and biomedical applications with profound scientific practice since past few decades. However, there is an imperious need of advancement in the field of compression therapy to manage lymphatic and phlebological disorders such as leg ulcer, varicose veins, and venous stasis. Gravity is the main cause to have chronic disorder in the lower extremities of the leg due to abrupt venous flow towards heart. Compression therapy applies certain amount of pressure around the affected area to push the venous back and the present candidates available are textiles fibrous based bandages and stockings. Current compression stockings have several shortcomings such as no external pressure control, lack of massage effect, and different class of stockings for different level of pressure. Pressure loss over time is the major issue in the bandages or stockings due to inherent properties of fibers such as cotton, polyester, nylon, and spandex. In addition, stress relaxation is most common in these fibers. Several attempts have been done by others to design different modalities but none of them are successful and not feasible for the practical applications. We have chosen the right material and discovered a novel phenomenon called "stress-memory" in a semi-crystalline memory polyurethane $[1,2]$. Where, the stress in the material can be programmed, stored, and retrieved reversibly upon an external heat stimulus. Before designing the smart stocking, there are some challenges ahead:

\section{Challenges:}

1) Optimization of material composition and its actuation temperature

2) Optimization of stress-memory and the relaxation property

3) How to integrate the smart memory polyurethane into stockings and optimize the stocking structure?

4) How to achieve the right pressure level and control externally?

5) What are the parameters to control the stocking pressure with textile structures and its relationship?

\section{Our Approach}

We have optimized the memory polymer composition and its transition/actuation temperature around normal usable range to retrieve the stored stress upon external heat [1-3]. Novel stress-memory programming procedure has been shown to get the stabilized memory stress without loss to avoid the pressure 
loss over time. Proper programming conditions to be followed to obtain the pure memory stress. A phase transition based constitutive model was recently to quantitively analyze the total stress-strain components in the memory polymer. Prediction of pure memory stress under given temperature at certain strain level revealed by using the memory/relaxed modulus which was shown with new methodology [4]. Memory filaments/ fibers were recently produced via melt spinning method and studied its stress-memory behavior comprehensively via mechanical and structural characterization approach [5]. We have found that, filaments can store and retrieve maximum level of memory stress than film and the ascribed reason is the perfect crystallization and orderly packed molecular chains of the soft segment. Recently we have optimized and selected the appropriate textile structure to integrate stress-memory filaments to design a multi-functional smart stocking where the interfacial pressure can be controlled externally via thermal stimulus. The stress-memory filaments integrative multifunctional smart stocking unifies pressure gradient, massage effect, selective pressure control, easy size fitting, and one size stocking for all. The level of the pressure/massage can be easily controlled by textile structures and physical parameters such as deformation range and temperature level as needed.

\section{Conclusion}

Right from the discovery of novel stress-memory behavior in stimulus responsive memory polymer, we have been continuously putting our efforts to optimize the polymer, fibers/filaments, and stocking structures towards designing the multi-functional smart compression stockings. The advent of this novel concept and scientifically applying into stockings leads to revolutionary changes in compression therapy into one step advanced level with smart functions. The stress-memory filaments integrative smart fabrics could also be implied into other diversified numerous applications where the stimuli responsive force is needed.

\section{Acknowledgement}

The authors would like to thank the financial support from the Hong Kong Research Grants Council (RGC) with General Research Fund (GRF), Project number: PolyU 15204416) and National Natural Science Foundation of China (Grant No. 51373147).

\section{Conflict of Interest}

The authors do not have any conflict of interests.

\section{References}

1. Hu JL, Kumar B, Narayana H (2015) Stress memory polymers. J Polym Sci Pol Phys 53(13): 893-898.

2. Hu JL, Zhu SS, Young RJ, Cai ZQ Li LB, et al. (2017) Stress memory materials and their fundamental platform. J Mater Chem A 5(2): 503511.

3. Hu JL, Narayana H, (2017) Novel Behavior in Smart Polymeric Materials: Stress Memory and its Potential Applications. Advances in Science \& Technology 97.

4. Narayana H, Hu JL, Kumar B, Shang SM (2016) Constituent Analysis of Stress Memory in Semicrystalline Polyurethane. J Polym Sci Pol Phys 54(10): 941-947.

5. Narayana H, Hu J, Kumar B, Shang S, Han J, et al. (2017) Stress-memory polymeric filaments for advanced compression therapy, Journal of Materials Chemistry B 5(10): 1905-1916.

\section{Your next submission with Juniper Publishers} will reach you the below assets

- Quality Editorial service

- Swift Peer Review

- Reprints availability

- E-prints Service

- Manuscript Podcast for convenient understanding

- Global attainment for your research

- Manuscript accessibility in different formats ( Pdf, E-pub, Full Text, Audio)

- Unceasing customer service

Track the below URL for one-step submission https://juniperpublishers.com/online-submission.php 